\title{
Actores económicos y políticos en las reformas institucionales de las metrópolis europeas *
}

\section{Christian Lefèvre ***}

\section{Introducción}

Los años sesenta y setenta fueron un período de referencia de las reformas de la organización institucional de los territorios infranacionales en Europa, e incluso en el mundo occidental en general. El objetivo era principalmente hacer coincidir los territorios administrativos del Estado y de las entidades locales con los espacios funcionales que se desarrollaban rápidamente por la urbanización. Así pues, estas reformas eran, ante todo, acciones dirigidas por el centro —el Estado o los Estados federados en los países federales - en nombre de una necesaria racionalización de las estructuras territoriales.

Las áreas metropolitanas han sido evidentemente afectadas por estas reformas, pero de manera desigual en los distintos países. El balance que se puede hacer se manifiesta más bien negativo (LEFĖVRE, 1998). Prueba de ello es que se ha abierto un nuevo período de puesta en marcha de reformas institucionales en el nivel de la adecuación entre los territorios institucionales y los territorios funcionales (BENNET, 1989) desde comienzos de los años noventa.

No es nuestro propósito, en el marco de este artículo, realizar un primer balance del éxito o del fracaso de estas reformas, considerando por tales tanto la creación de nuevas instituciones que cubran el territorio metropolitano como el fortalecimiento de las estructuras existentes en ese territorio. Por otra parte, esa labor ya se ha hecho en el caso de varias ciudades (JouvE y LEFĖVRE, 1999, 2001). Nuestra ambición es más bien, tomando como objeto de análisis estas reformas en la actualidad, deducir algunos elementos de comprensión de la evolución del poder local de las grandes ciudades europeas. En efecto, las reformas institucionales de las metrópolis (RIM) constituyen un buen campo de estudio del poder local en la medida en que, a diferencia del período anterior, las reformas en curso reclaman otros actores diferentes de los políticos y especialmente a los medios económicos. En este sentido, como veremos, integran perfectamente la evolución de las políticas públicas en un marco que numerosos autores han intentado captar a través del término «gobernanza urbana». Además, las reformas actuales han cambiado de registro de justificación, ya que a la necesidad de ofrecer infraestructuras y servicios a las poblaciones ha venido a sumarse la exigencia de dotar a las aglomeraciones de un sistema institucional apto para ganar la competencia internacional que los territorios libran entre ellos (GoR. DON Y CHESHIRE, 1996).

Desde esta perspectiva, el análisis del poder local a través de los procesos de reformas institucionales reenvía directamente a la cuestión de la gobernabilidad urbana en la que se supone que se integran estas reformas. Los trabajos en marcha en varias metrópolis europeas vienen, pues, a cuestionar esta noción de gobernabilidad en la medida en que, por una parte, planteamos la gobernabilidad como algo por construir, más que como algo alcanzado, y, por otra parte, que construimos la hipótesis de que debido a que la fragmentación incrementa las esferas de la política y de la economía, esta gobernabilidad parece cada 
vez más improbable, al menos en el nivel del territorio global de la metrópoli.

Por eso este artículo se divide en tres partes. En la primera haremos la presentación de las reformas institucionales como proceso de acción colectiva hoy en día, y situaremos en ellas los retos teóricos que los actores políticos y económicos pueden encontrar. En la segunda parte nos centraremos en la actitud de los medios económicos y más especialmente en las estructuras de representación frente a los procesos de reformas institucionales. Finalmente, en una tercera parte conclusiva examinaremos la cuestión de la gobernabilidad de las ciudades a través de lo que pueden explicarnos los procesos que conducen a reformas institucionales.

\section{Acción colectiva y RIM en los años 1990-2000}

La acción colectiva se ha transformado profundamente en el curso de los diez o quince últimos años. Ampliamente dominada por los poderes públicos, y en algunos casos (Francia, Italia y Reino Unido) incluso completamente monopolizada por éstos, ha experimentado posteriormente un verdadero cambio de paradigma que se encuentra por lo demás en los términos empleados hoy en día, cuando no se habla ya de acción pública para designar las políticas desarrolladas, sino de acción colectiva.

Este cambio de paradigma se explica en parte por un decaimiento de la manera clásica de gobierno de las sociedades europeas, que se pone de manifiesto en la incapacidad de esta forma para diagnosticar - y a fortiori para resolver - un gran número de problemas cruciales como los de la violencia y la inseguridad, la conservación del medio ambiente, el paro, etc. Esta forma clásica de dirección de las sociedades se basaba en una centralidad de los poderes públicos, y especialmente del Estado, centralidad considerada legítima por la sociedad en la medida en que el sector público se mostraba capaz de realizar un análisis de los problemas existentes, disponía de expertos y de recursos para hacerles frente y se mostraba capaz de proponer y de aplicar una visión del futuro.

La pérdida de centralidad de los actores públicos —que sin embargo resulta, desde muchos puntos de vista, más teórica que real - se ha realizado mediante la apertura del sistema de actores de las políticas públicas hacia la sociedad civil, considerada progresivamente como detentadora de los conocimientos y del saber hacer de los que adolecían cruelmente las autoridades políticas. Fue así como las empresas fueron llamadas al debate y en algunos países como el Reino Unido para decidir las políticas que había que implementar en el campo del desarrollo económico. En los ámbitos sociales y tratándose de la calidad de vida (medio ambiente, cultura, educación...) los habitantes fueron invitados a participar en la elaboración de las acciones, bien por la vía de medios asociativos, bien directamente mediante consejos de barrio u otras formas de democracia participativa.

La apertura del sistema de actores a la sociedad ha transformado profundamente la lógica misma de la elaboración y la aplicación de las políticas públicas. Anteriormente, el sentido de la acción era aportado totalmente por el detentador de la legitimidad, muy a menudo el Estado. Las políticas públicas eran presentadas, e impuestas, diseñadas y con los recursos correspondientes. En la actualidad ya no ocurre así. La acción colectiva se inventa a medida de los debates y de las confrontaciones de opiniones entre los actores. Para retomar una fórmula que ya es clásica, hemos pasado de lo sustancial a lo procedimental, en la media en que hoy en día la acción colectiva se realiza necesaria y principalmente a través de procesos que permiten que la sustancia y el sentido de esa acción se elaboren.

Es evidente que esta presentación resulta excesivamente sintética. Espacios completos de políticas públicas permanecen controlados por las autoridades públicas, especialmente por el Estado. Pero incluso en esos sectores, el sector público que domina no es igual que antes. Menos seguro de su autoridad y de su legitimidad, más inclinado a entenderse con la sociedad civil, intenta más establecer los marcos de los debates sobre la acción que a realizarla realmente. Efectivamente, se dio cuenta de que ya no podía asumir el conjunto de ámbitos de la acción pública, de que ya no podía intervenir por medio de la imposición autoritaria. Entonces se volvió más modesto, en medio de redes de actores menos estables porque evolucionan según los sectores y el período considerado. Por su parte, el Estado, que también está afectado por esos cambios, debe interactuar con los otros niveles de entidades locales.

Las políticas institucionales y especialmente las reformas de la organización político-territorial de las metrópolis europeas no escapan a esto cambios, aunque su campo específico, las forma de organización del poder político, remite de forma más directa que otros a los actores propiamente políticos que son las instituciones locales. Esto es lo que nosotros vamos a ver en una primera sección, antes de centrarnos en los retos que los actores políticos y económicos ven en estas reformas.

\section{Las RIM: Las nuevas formas de la acción pública}

Muchas de las reformas de las instituciones metropolitanas contemporáneas constituyen una prueba de una nueva concepción de la creación institucional. En efecto, mientras que en el período precedente las instituciones metropolitanas se rea- 
lizaban sobre un modelo pret-à-porter donde el territorio cubierto, las competencias transferidas u obtenidas, los recursos financieros y fiscales, la forma de elección de los consejos ejecutivos y de las asambleas eran propuestos y hasta impuestos de forma definida, en muchos países ya no ocurre así en la actualidad. La institución se considera como algo por hacer, como el resultado de un proceso de construcción cuyo resultado aparece súbitamente. Los países caracterizados aún por un fuerte centralismo, como Francia, Holanda y el Reino Unido, no escapan a este fenómeno y la construcción institucional es objeto cada vez más de la búsqueda de un consenso, producto de una dinámica en la que se mezclan múltiples actores. El proceso que ha conducido a la creación de la Greater London Autbority puso de manifiesto plenamente esta evolución. Hay, en efecto, una amplia consulta de las fuerzas vivas del país a partir de las primeras propuestas gubernamentales, que se transformaron en libro blanco y luego en proyecto de ley. La línea italiana, con las ciudades metropolitanas, lleva este proceso al extremo, como lo demuestra el intento de constitución de la Città Metropolitana de Bolonia (Jouve y LefĖvre, 1996).

La Ley 142 italiana de 1990 dispuso que las diez mayores aglomeraciones debían dotarse muy rápidamente de nuevas instituciones denominadas Città Metropolitana (CM). Hasta 1994 no se hizo nada, y el Estado no intervino. En Bolonia, el año 1994 vio la forma de un acuerdo, el Acuerdo por la Ciudad Metropolitana (ACM), cuyos signatarios (la provincia de Bolonia y la mayor parte de los municipios incluidos en ella) aceptan crear estructuras comunes de reflexión y de actuación en los campos de los asuntos administrativos, la acción sanitaria y social, la economía y el territorio. La idea es la de invertir el proceso de constitución institucional. Anteriormente, se creaba la institución y las políticas iban detrás, en el mejor de los casos. Aquí, se trata de primeramente de establecer políticas en los campos precitados y dar así vida y sentido a un territorio, el área metropolitana y su población. Las políticas públicas no sólo preceden a la institución, sino que la hacen necesaria, porque es mediante la acción conjunta de los socios como se afronta y se resuelven en parte un cierto número de cuestiones. Se trata, pues, de articular una dinámica mediante la acción colectiva y actuar de forma que esta dinámica desemboque en una creación institucional. En el caso boloñés, la dinámica se paró después de las elecciones municipales de 1999, cuando la izquierda cedió el puesto al centro-derecha por primera vez después de la guerra. Pero entre 1994 y 1999 se transformaron las estructuras de trabajo en oficinas metropolitanas donde se fusionan los servicios de la provincia y del municipio de Bolonia y donde se incorporan a veces otros municipios. Encontramos en Francia un proceso del mismo tipo con la Ley de 1999 que obliga a los municipios de una misma aglomeración a agruparse en la que se llamará una comunidad de aglomeración o una comunidad urbana, pero que para ello exige que antes se elabore y se apruebe un proyecto de aglomeración, que es una especie de libro blanco que define las orientaciones y las prioridades y que servirá en parte al Estado para asentar sus políticas en el nivel local.

Esta nueva concepción de la creación institucional se realiza generalmente en nombre de la voluntariedad y de la flexibilidad. Voluntariedad porque un municipio no está obligado a entrar en la futura institución metropolitana. Flexibilidad porque su entrada puede realizarse de forma gradual. En estos aspectos es significativa la experiencia bolonesa. La ACM sólo fue firmada por las entidades territoriales que lo deseaban, es decir, por 48 de los 60 municipios que integran el territorio de la provincia de Bolonia, además de la propia provincia de Bolonia. Estos municipios se han implicado de forma progresiva y diferenciada en las reflexiones y las acciones conjuntas. Volvemos a encontrar esta voluntariedad y flexibilidad en el caso francés, donde las instituciones metropolitanas pueden escoger alguna de sus competencias, e incluso decidir o no una fiscalidad común.

Sin embargo, la creación institucional no se ha dejado al azar o a la simple buena voluntad de los actores locales. En efecto, casi siempre se encuentra enmarcada por un procedimiento que puede ser más o menos elaboradó y obligatorio según los casos. De esta forma, el procedimiento va a determinar el ritmo del proceso institucional, aportando decisiones sobre las etapas que precisan en cada caso el contenido y la sustancia de la futura institución, realizando todo ello sobre la base de la búsqueda del consenso. El procedimiento puede originar también la creación de estructuras encargadas de su aplicación y que pueden prefigurar la nueva institución. En Bolonia, la ACM es antes que nada un acuerdo que fija un procedimiento. En efecto, establece un calendario de la innovación institucional con una ley regional que debe fijar el territorio y las competencias precisas de la Ciudad Metropolitana y un referéndum sobre el proyecto. Además, la ACM crea dos estructuras de funcionamiento y de seguimiento del proceso: la conferencia metropolitana y la secretaría de la conferencia. La conferencia metropolitana es un órgano político que reúne, bajo la égida de la provincia, a los municipios firmantes del Acuerdo. Los municipios no firmantes son invitados siempre en calidad de observadores y pueden incorporarse a la ACM en cualquier momento. Esta conferencia se reúne muy regularmente y es la que define el programa y el contenido del trabajo de las estructuras técnico-administrativas conjuntas (las oficinas metropolitanas). Está asistida por una secretaría, dirigida por el Teniente de Alcalde de Bolonia, que es de hecho la estructura de dirección de la ACM. Encontramos procedimientos del mismo tipo, si bien menos estructurados o formalizados, en otros países europeos o en otras metrópolis como Stuttgart o Lyon. En esta última ciudad, el proyecto de Región Urbana ha sido liderado durante mucho tiempo por una conferencia integrada por los Presidentes de los departamentos y 
el Presidente de la Comunidad Urbana de Lyon, conferencia que ha hincado diversos procesos de los que algunos han finalizado en documentos que fijan las orientaciones de la futura institución, como es el caso de la Carta de Desarrollo.

La cuestión de la legitimidad, crucial para la aplicación de las instituciones de aglomeración (LeFĖVRE, 1998), tampoco se olvida en las nuevas reformas. Efectivamente, se abordan dos puntos fundamentales que están pendientes de resolverse. Por una parte, la cuestión del poder institucional en el área urbana, por otra, la legitimidad democrática.

Las instituciones metropolitanas creadas en las décadas precedentes han sufrido profundamente la competencia, e incluso el control de las ciudades centrales. La mayor parte de las leyes recientes han intentado reducir o eliminar este problema, en la medida en que, a diferencia de sus predecesoras, se dirigen a crear un poder de aglomeración fuerte, que exige un debilitamiento del de los municipios centrales, ya que estos dos poderes fuertes no pueden coexistir en un mismo espacio. Así, la Ley italiana de 1990 y los proyectos holandeses de los años noventa habían previsto una desaparición pura y simple de las ciudades centrales, dividiéndolas en varios municipios. Los proyectos de Amsterdam y de Rotterdam preveían, en efecto, la constitución respectiva de una decena de nuevos municipios en el lugar de las ciudades actuales. En Milán, veinte municipios debían sustituir a la ciudad central. En el caso boloñés, se han previsto nueve municipios. En Francia, todos los debates actuales se dirigen hacia el debilitamiento de los municipios, que sólo podrían conservar competencias de proximidad, un poco a la imagen de las ciudades de París, Lyon y Marsella (Senado, 2000).

Estas leyes han manifestado rápidamente su impracticabilidad. Resulta evidente que no han obtenido en ninguna parte el apoyo de los municipios que iban a desaparecer (véase la sección 2). Pero sobre todo, han tropezado con sus mismos habitantes. Efectivamente, con una inquietud democrática que hay que saludar, las creaciones institucionales actuales deben ser aprobadas por los habitantes, generalmente mediante un procedimiento de referéndum. Los de Amsterdam y Rotterdam en 1995 constituyeron un verdadero desaire para los defensores de las instituciones metropolitanas, al oponerse más de un 90 por 100 de los electores a la creación de un Gran Amsterdam o de un Gran Rotterdam, sobre todo porque esto significaba al mismo tiempo la desaparición de antiguos municipios de varios siglos. También la Ley italiana de 1990 preveía el uso del referéndum. Por el momento, no se ha celebrado ninguno y la metrópoli más avanzada en esta línea, Bolonia, ha dudado durante mucho tiempo por temor a un voto negativo de sus habitantes. El único referéndum positivo fue el de la creación de la Greater London Autbority en 1999, pero, aparte del bajo porcentaje de participación, este resultado puede explicarse por la situación propia de esta gran metrópoli, en la que se entre- mezclan decenas de entidades territoriales y de «partenariados» público-privados, y donde nunca se ha tratado de suprimir los municipios existentes.

Como se puede ver, las nuevas reformas institucionales de las grandes aglomeraciones retoman ampliamente las nuevas formas de la acción pública. Sin embargo, no es seguro que esas nuevas líneas de actuación y esos nuevos procedimientos ofrezcan resultados más convincentes que las reformas anteriores. Los trabajos recientes en la materia (JouvE y LEFĖVRE, 2001) hacen pensar más bien lo contrario, en la medida en que cualquier creación institucional de estas dimensiones hace surgir desafíos de poder que las nuevas formas de acción pública no tienen capacidad de resolver. Vamos a centrarnos hora en los retos que plantean o pueden plantear las reformas del gobierno en las grandes ciudades para los actores políticos y los económicos.

\section{Los retos de las RIM para los actores políticos}

Los actores políticos son numerosos y heterogéneos. Su heterogeneidad se basa en tres elementos: su lugar en el sistema institucional, su localización geográfica en el interior de la aglomeración y su posición en las estructuras de poder. Los actores políticos considerados por su lugar en el sistema institucional son las entidades territoriales, es decir, el Estado, las regiones, las entidades intermedias (departamentos, provincias, kreise, etc.) y, finalmente, las entidades básicas, generalmente los municipios. La localización geográfica reenvía a la dicotomía entre centro y periferia en la aglomeración, es decir, entre ciudades centrales y municipios periféricos. Finalmente, la posición en el seno de las estructuras de poder pone el acento en los actores políticos que son los partidos, pero también en los electos, analizando si ocupan posiciones mayoritarias o minoritarias, dominantes o marginales en el sistema político local.

Es evidente que este tipo de hetereogeneidad de los actores políticos juega fuertemente sobre sus percepciones de las reformas institucionales, definiendo para cada uno de ellos retos específicos, porque el fundamento de las reformas institucionales consiste en que cambian los espacios del poder. En este sentido, otorgar poder al espacio metropolitano cuestiona el sistema establecido, su funcionamiento, sus formas de regulación, lo que favorece a algunos actores en detrimento de otros.

El Estado ha jugado siempre un papel ambiguo con respecto a los gobiernos metropolitanos, aunque su actitud difiera según la concepción política de la democracia ${ }^{1}$. En Francia, el Estado juega hábilmente rechazando la idea de crear verdaderas entidades locales en el nivel metropolitano. Siempre ha preferido establecer estructuras sin legitimidad política directa basadas en el principio de «cooperación intermunicipal» (LEFĖVRE, 1997). Hasta una fecha muy reciente, su concepción de una 
institución metropolitana se basaba principalmente en una lógica funcional, es decir, que era necesario crear estructuras capaces de asumir el desarrollo del territorio sin darles por ello una legitimidad política directa ni recursos adecuados. Esta concepción se encuentra también en Holanda, donde el Estado ha preferido una desconcentración funcional en el nivel de los territorios urbanos antes que una verdadera descentralización (KREUKELS, 1999). Detrás de estas estrategias estatales se esconde de hecho el temor del Estado de que se creen estructuras políticas locales suficientemente poderosas para convertirse en contrapoderes de su autoridad. En Gran Bretaña, si bien la constitución de los condados metropolitanos se justificaba parcialmente por la necesidad de crear contrapoderes al Estado (en un contexto de checks and balances), la etapa thatcheriana rompió este equilibrio y se saldó con la abolición pura y simple de esos condados. El renacimiento del Gran Londres no supone, a pesar de todo, un paso contra esta evolución, porque el gobierno quiso una GLA más bien débil en relación con su predecesor, el Greater London Council (KıEINMAN, 1999).

Esta desconfianza de los Estados frente a unas poderosas autoridades metropolitanas se encuentra también de forma evidente en las entidades básicas, los municipios, que tienen muchas competencias y recursos que perder. El Estado francés ha sabido jugar con esta rivalidad potencial y las leyes de des. centralización se han hecho en beneficio de los municipios y los departamentos, quedando olvidado hasta la actualidad el poder de las aglomeraciones. De esta forma, los municipios han hecho valer su legitimidad como célula básica de la democracia frente a «gargantúas» tecnocráticos y alejados de las preocupaciones de los habitantes. Los municipios italianos han jugado la misma carta. Sin embargo, desde la Ley de 1990 se han puesto de manifiesto diferencias. Si la ciudad de Milán se opuso a su división y, por lo tanto, a su desaparición, no ocurre lo mismo en las de Bolonia y Roma, lo que se explica en parte por los políticos y los líderes existentes en la etapa de los proyectos de ciudades metropolitanas (JOUVE y LEFĖvRE, 2001). Sin embargo, es innegable que se están produciendo sensibles cambios por diversos motivos, y las cosas se están moviendo en el nivel de las ciudades centrales. Así, en el caso de Stuttgart, los problemas fiscales y la necesidad de hacer que las ciudades del extrarradio compartan las cargas de centralidad, hasta entonces soportadas esencialmente por la ciudad central, han precipitado su adhesión a la región urbana (Verband Regio Stuttgart) (Frenzel, 2001). Hoy día es un leitmotiv de las ciudades centrales francesas, ampliamente representadas por la Asociación de los Alcaldes de las Grandes Ciudades de Francia (AMGVF), muy favorables a la elección mediante sufragio universal directo de las futuras comunidades urbanas y de aglomeración. En Holanda, son las ciudades de Amsterdam y Rotterdam los motores de los proyectos de creación de las ciudades-provincia. Por lo tanto, si la perspectiva de la creación de poderosas instituciones metropolitanas es vista con descon- fianza y hasta con hostilidad por numerosos municipios de la periferia urbana, no se puede decir lo mismo de las ciudades centrales.

Las entidades intermedias tienen retos contradictorios. Por una parte, según la configuración espacial de la urbanización, algunas de ellas pueden convertirse en las futuras instituciones de aglomeración. Es el caso de alunas provincias urbanas italianas como la de Milán o la de Bolonia, que se verían vestidas con los hábitos de las ciudades metropolitanas; pasarían entonces de un estatuto de instituciones «vestigio», que disponen de pocas competencias y recursos, a la de verdaderos gobiernos de aglomeración, dotados de competencias estratégicas y numerosas y de recursos significativos. También es el caso de determinados departamentos urbanos en Francia, como los Bouches du Rhône (Marsella) o de algunas provincias holandesas. Por otra parte, las entidades intermedias tiene mucho que perder. Al encontrarse cogidas entre unas poderosas instituciones metropolitanas y una regiones con fuerza creciente, su función parece cada vez más superada y los debates sobre la supresión de los departamentos franceses o sobre la amputación de las provincias holandesas e italianas, e incluso de algunos cantones suizos (como el de Zurcí) son de una rabiosa actualidad.

La posición de las regiones varía según su peso político-institucional. En los Estados unitarios o de federalismo débil (España, Italia) pueden considerar a las instituciones metropolitanas como rivales y oponerse entonces al aumento de su poder. El debate italiano sobre la entrada de las futuras ciudades metropolitanas en un senado que no sería únicamente el de las regiones pone de manifiesto este conflicto. Por el contrario, en los Estados federales como Alemania, el Land, poderoso por su legitimidad constitucional y por las enormes competencias de que dispone (especialmente sus potestades de tutela de las entidades locales), puede jugar un papel favorable a la constitución de instituciones metropolitanas. El caso de Verband Regio Stuttgart (VRS) es emblemático de una situación en la que la VRS nunca habría visto la luz ni la constante presión y las amenazas del Land de Bade-Wurtemberg sobre los municipios periféricos (FRENZEL, 2001).

Como cualquier acontecimiento que cambia las reglas del juego y, por lo tanto, los espacios del poder, las reformas institucionales en las áreas metropolitanas van a enfrentarse con los actores que se diferencian por su posición en las estructuras existentes de poder. De forma muy clara, los que están excluidos del poder o son marginados de su funcionamiento actual tienen todo que ganar en el establecimiento de las reformas. En este registro, dos tipos de actores son especialmente importantes: los partidos políticos y los electos o los que aspiran a serlo.

Los partidos tradicionales, los que han creado los sistemas institucionales existentes y que se sirven de ellos para asentar 
su autoridad, van a tener tendencia a oponerse a las reformas o, cuando menos, a impedir un cuestionamiento radical de la organización existente. Se basarán en los más «iluminados» de entre ellos para realizar unas reformas graduales que puedan controlar. Por el contrario, los nuevos partidos políticos, como los Verdes en Francia y Alemania, o los autonomistas (las Ligas en Italia, por ejemplo), van a intentar promover las reformas porque así pueden esperar tomar el poder en las nuevas instituciones locales. Por el momento, estos partidos se han centrado más bien en el nivel regional (los Verdes en Francia y en Alemania, los autonomistas en España y en Italia), sin que el área metropolitana aparezca como un reto territorial fuerte. Pero detrás de estas estrategias políticas —que no reflejan una oposición clásica entre izquierda y derecha- se perfila sin embargo una concepción institucional del gobierno territorial radicalmente diferente. El caso francés expresa bien esta situación. Los «modernos» (los Verdes, una franja del Partido Socialista y de la derecha neoliberal) se pronuncian por una organización territorial basada en la tríada «Europa, Región, Metrópolis», y se oponen a los «antiguos» que permanecen vinculados a la tríada «Estado, Departamento, Municipio», fundamento del Estado-nación a la francesa.

Si los partidos marginales o menos anclados en el sistema político son favorables a las reformas, se puede decir lo mismo de ciertos políticos, incluidos los pertenecientes a los partidos dominantes. Hemos demostrado claramente (Jouve y LEFÈVRE, 2001) que los electos locales favorables a las reformas metropolitanas en las grandes ciudades europeas se caracterizan por unas características específicas que lo sitúan al margen o al menos en contradicción con su partido. Se trata de políticos más bien jóvenes, para algunos menos bien posicionados en las instancias dirigentes nacionales, menos respetuosos con las reglas de avance en la carrera y por ello menos fiables para el partido que representan en el nivel local. M. Noir en Lyon, W. Vitali en Bolonia, A. Bassolino en Nápoles, B. Pepper en Rotterdam se han convertido en los postuladores (BAssolino, 1997) de un gobierno metropolitano basando su legitimidad más en su capacidad personal para dirigir la aglomeración que en su pertenencia, sobre todo ideológica, a cualquier partido político. Aun así, este posicionamiento de los electos a favor de los gobiernos de aglomeración trasciende de las fracturas políticas clásicas, porque estos políticos se encuentran en un punto que les parece más allá de las discrepancias partidistas: su legitimidad debe provenir más de su capacidad para gobernar su territorio, es decir, de aplicar políticas públicas, que de su pertenencia a un partido. En este contexto, el partido se convierte en algo casi secundario, lo que obliga a los electos a ampliar su base de apoyo, especialmente recurriendo a los medios económicos. Pero, ¿por qué estos actores habrían de implicarse en estos procesos?

\section{Los retos de las RIM para los actores económicos}

Al igual que los actores políticos, los medios económicos son muy heterogéneos y su hetereogeneidad predetermina ampliamente los retos que asocian a las reformas institucionales y como consecuencia su implicación en los procesos de aplicación de estas reformas. Tenemos que enfrentarnos aquí con un vacío tanto del análisis teórico como de los trabajos empíricos sobre esta cuestión, si bien no es posible hoy en día, a diferencia de los actores políticos, alcanzar explicaciones satisfactorias sobre el comportamiento de los medios económicos. De forma más modesta, trataremos de precisar en esta sección las razones que podrían o deberían hacer de los actores económicos socios activos de la política. En la segunda parte de este artículo nos centraremos, por el contrario, en su comportamiento efectivo.

Para nuestro propósito, hemos identificado tres tipos de actores económicos en función de su capacidad para elaborar y aplicar estrategias, requisito previo para una implicación en procesos de recomposición institucional en el nivel metropolitano.

Las empresas son agentes diversificados en su tamaño y en sector de actividad. Por una parte, nos encontramos con PYMEs que sólo tienen escasa capacidad estratégica por sí mismas, prefiriendo centrarse en su propia actividad y en su desarrollo y que no disponen de recursos suficientes para intervenir por sí mismas sobre el territorio, y a fortiori sobre el funcionamiento político de ese territorio. Por otra parte, encontramos grandes empresas, capaces de estrategias propias y disponiendo de recursos importantes para hacerlos valer, especialmente frente a los poderes públicos. En tercer lugar, los medios económicos se han organizado durante décadas y han creado, más o menos libremente, estructuras de representación como las cámaras de comercio o las uniones patronales, que poseen recursos específicos y que según los casos pueden elaborar estrategias adecuadas.

Si bien encontramos estos tres tipos de actores en las metrópolis europeas, sin embargo no podemos efectuar un análisis generalizado de sus retos y de su comportamiento frente a las reformas institucionales. En efecto, la hetereogeneidad de los medios económicos aumenta con la diversidad de las situaciones europeas. Por ejemplo, si encontramos formas de estructuración y de representación de los medios económicos en todos los países europeos, esas formas pueden diferir en gran medida según el país considerado. En Francia, en Alemania o en Italia, las $\mathrm{CCI}^{2}$ son organismos públicos poderosos que engloban de derecho al conjunto de las empresas. No es el caso del Reino Unido, donde las CCI son asociaciones voluntarias que disponen de competencias y de recursos mucho menores. Por eso encontramos en este país otras estructuras de representación ad boc, de estatuto diferente y que pueden jugar, según los casos, un papel mucho más grande que las cámaras de comercio. 
Si en algunos países, como Francia o el Reino Unido, las cooperativas juegan escaso papel en el desarrollo económico y las políticas urbanas, no ocurre lo mismo en otros, como Italia y Holanda, donde estas forma de organización son importantes y se presentan como socios ineludibles de las autoridades políticas.

Podemos afirmar, pues, como punto de partida en lo que se refiere a las reformas institucionales, que no hay retos comunes a los actores económicos, es decir, objetos de confrontación pertinentes para todos sobre el funcionamiento del conjunto del territorio metropolitano. En el plano teórico, los análisis ya no nos ayudan por las razones siguientes. Por una parte, la mayoría de las teorías existentes se interesan solamente por las empresas y no por sus estructuras de organización. Pues bien, nosotros vamos a comprobar cómo, con la excepción siempre relativa de las grandes empresas, la acción de las firmas con relación a las reformas institucionales se realiza principalmente por medio de estructuras colectivas como las CCO o las uniones patronales. Por otra parte, la mayoría de las teorías existentes se interesan esencialmente por el desarrollo económico, sin tener en cuenta prácticamente nunca las políticas institucionales.

Sin embargo, algunas teorías que se interesan por las relaciones entre empresas y territorios, especialmente en las grandes metrópolis, distinguen algunos objetivos que deberían explicar el comportamiento de los medios económicos frente a las reformas institucionales, dado que no se trata de objetivos compartidos por el conjunto de los actores económicos, sino por el contrario, objetivos propios de cada uno de los tres tipos de actores anteriormente identificados.

3.1. La dependencia de lo local. La teoría de la dependencia de lo local (local dependence), desarrollada a fines de los años ochenta por K. Cox y A. MaIr (1988), trata de identificar los tipos de actores que por sus características deben intervenir en el gobierno de los territorios. Estos dos actores consideran que para algunos actores el buen funcionamiento del territorio, de lo local, es crucial, porque esos actores dependen de la reproducción de algunas relaciones sociales sobre un territorio particular sin las que no se puede sobrevivir y desarrollarse. Desarrollan esta afirmación sobre el caso de las firmas en las que la empresa capitalista depende para su reproducción de intercambios que tienen una expresión geográfica clara y que se corresponden con el área de empleo, el área de clientes, etc. Estas relaciones de intercambio no son estables, ni en el tiempo ni en el espacio. Si algunas firmas pueden adaptarse a las evoluciones de los flujos de valores, cambiando por ejemplo de suministradores o de subcontratistas o deslocalizándose, no ocurre lo mismo con todas. En esos casos, estas últimas se denominan «localmente dependientes». Se trata de firmas que invierten en el entorno construido y cuyas inversiones son tales que sólo pueden amortizarse a largo plazo.
Las empresas cuyas inversiones son geográficamente limitadas dependen, pues, de la marcha del territorio en el que se sitúan, en la medida en que las inversiones que pueden realizar son relativamente inmóviles. Se trata en primer lugar de las empresas de suministros (redes) (public utility companies) que disponen de grandes infraestructuras y de equipamientos fijos, pero también de instituciones financieras que han invertido fuertemente en la propiedad inmobiliaria local. Se trata también de las empresas para las cuales lo local posee características especiales y necesarias que difícilmente podrían encontrar en otra parte. Cox y MaIr hablan entonces de «insustituibilidad de las relaciones de intercambio localizadas en las que la estabilidad es importante para el beneficio», es decir, de empresas cuya deslocalización es difícil y hasta imposible. Esas relaciones de intercambio insustituibles pueden ser la confianza, la capacidad de prever la evolución en un medio del que no se conocen las principales variables, las buenas relaciones con el poder político o los demás actores sociales o incluso los demás actores económicos. Las empresas afectadas son las compañías de seguros, las promotoras inmobiliarias, los medios de comunicación locales, las empresas dependientes de una mano de obra particular, etc.

Las empresas que dependen de lo local deben, pues, intervenir en el gobierno de su territorio, porque sólo difícilmente pueden desarrollar estrategias dirigidas a reducir esta dependencia, como la deslocalización o la multilocalización que reduce los riesgos. Intervienen a fin de conservar las características del entorno construido que lo hacen insustituible: mantenimiento y desarrollo de los activos inmobiliarios, conservación y ampliación de una clientela o de usuarios cuya presencia y solvencia garantizan los beneficios empresariales, etc. La dependencia de lo local se presenta, pues, como el punto en común de algunos actores y especialmente de cierto tipos de empresas. A partir de este elemento común, según Cox y MaIR, las empresas pueden y/o van a crear coaliciones económicas locales (local business coalitions) a fin de influir en las orientaciones del desarrollo local operadas por los poderes públicos.

3.2. Otras teorías se interesan por los retos planteados por las propias instituciones. Así, el reto de las reformas institucionales para los actores económicos se encuentra sobre todo en la vieja polémica entre los partidarios de la public choice y los reformadores de los años sesenta (LEFĖVRE, 1998), en la que los reformadores atribuyen a las formas institucionales de gobierno de las ciudades, y especialmente a la identificación entre territorio funcional y territorio institucional (de forma que, grosso modo, la constitución de los gobiernos locales coincide con las áreas urbanas funcionales) un impacto determinante en el funcionamiento económico y social de la ciudad. Defender la constitución de una autoridad metropolitana es optar, nos dicen estos últimos, por políticas públicas más eficaces en términos de solidaridad, de armonía social y de crecimiento eco- 
nómico. En los años sesenta y setenta, tanto en los Estados Unidos como en el Reino Unido buena parte de las asociaciones patronales, como la Confederation of British Industry (CBI) o el Council for Economic Democracy en los Estados Unidos se han pronunciado claramente por reformas que se dirijan en ese sentido.

En segundo lugar, la calidad de la organización institucional, en opinión de algunos (GORDON y CHESHIRE, 1996; RACO, 1998; Amin y Thruft, 1995; WoOD, 1998), sería una baza en la competencia que se libra entre las grandes ciudades mundiales y que se ha exacerbado (o incluso iniciado) debido al proceso de globalización. Las instituciones locales jugarían así un papel de mediación entre los intereses locales y los procesos globales (Wood, 1998). El éxito económico de un territorio dependería de su «espesor institucional» (AmIN y ThRIFT, 1995) porque «las instituciones son cruciales para colectivizar las prácticas culturales, sociales y económicas que permiten a los territorios prosperar en la economía global» (RACO, 1998). La fragmentación institucional sería un freno al desarrollo de políticas dirigidas a desarrollar la competitividad de un territorio, porque supondría un obstáculo a la elaboración de estrategias para alcanzarla (GORDON y CHESHIRE, 1996).

En otro registro, las instituciones pueden contemplarse desde el ángulo de lo que B. GuY PETERs denomina la «institucionalización racional» (1997). En este marco, una de las principales razones para construir y desarrollar instituciones residiría en la minimización de los costes de transacción que permiten, costes que serían, pues, más importantes si no existiesen.

3.3. Otras teorías insisten más en la especificidad de algunos territorios para las empresas, como las metrópolis. En un contexto de mundialización, las firmas aplican estrategias que se centran cada vez más en la gestión del riesgo y de la incertidumbre (VelTZ, 1996). En este contexto, el territorio local ocupa un lugar cada vez más importante. En efecto, «la globalización de las firmas como estrategia de control de la diversidad supone una fina articulación con las especificidades locales de los mercados y, en general, de los contextos sociopolíticos» (Veltz, 1996: 112). Pero esto es así porque los territorios se convierten en un factor de gestión esencial para las empresas. Actúa como un espacio social concreto de interacciones mercantiles y no mercantiles que tiene un impacto sobre la competitividad de la empresa. Según el mismo autor, la mundialización conduce tendencialmente a una explosión de los costes de transacción y en general de los costes de organización de las regulaciones interempresariales. Por lo tanto, la concentración espacial sería una de las soluciones para reducir esos costes. Todo concurre entonces para hacer de los territorios urbanos, y especialmente de las grandes metrópolis, lugares específicos y cruciales para las empresas. Las metrópolis dispondrán así de una baza esencial para las firmas, como es el de ser lugares fuertes donde jugarían plenamente las «lógicas asegurativas» en todos los niveles (mano de obra, externalización de actividades, formación, más fácil ruptura de compromisos, etc.). Por lo tanto, la competencia territorial en un contexto de mundialización amplía considerablemente la noción de «dependencia local» de Cox y MArR, vinculando lo local a lo global y abriendo así los tipos de actores económicos susceptibles de movilizarse localmente. En tal contexto, se podría comprender que una forma multinacional, aparentemente «desterritorializada», invada el campo de las políticas locales.

En el contexto de la evolución económica descrita precedentemente, las instituciones juegan un papel específico. Lo local, y más específicamente lo urbano, se convertirá en uno de los nuevos espacios de la regulación de intereses, debido especialmente al declive del papel del Estado en este terreno. En el mismo orden de ideas, las instituciones, por su función de creación de certidumbre (o de reducción de incertidumbres) y de estabilidad de las relaciones entre actores, contribuirán a reducir los costes de transacción e incluso a jugar sobre la gestión de las firmas. La organización político-institucional sería entonces una ventaja comparativa en la competencia internacional a la que se libran las metrópolis en el nivel mundial.

Como se puede ver, los retos de las reformas institucionales también afectan a las empresas, pero estos retos varían según el tipo de firmas (PME frente a grandes empresas, empresas foot-loose frente las dependientes de lo local, etc.).

\section{El comportamiento de los actores económicos locales frente a las RIM}

La primera observación - y una de las más importanteses que la implicación de los actores económicos, bien directamente, bien por medio de sus organizaciones, no es la regla. En efecto, encontramos tantos casos en los que lo medios económicos se implican como en los que no. La primera cuestión a la que debemos aportar elementos de respuesta es, pues, la siguiente: ¿por qué los actores económicos no se implican en el gobierno de las ciudades?

\section{La no-implicación de los actores económicos}

Sin pretender la exhaustividad, es posible identificar cuatro tipos de explicación de la no-implicación de los medios económicos en las reformas institucionales: 1) las ciudades están bien administradas por la política; 2) hay una desconfianza de los medios económicos hacia la acción de los políticos; 3) el 
territorio local no es el lugar apropiado de intervención de las firmas, y 4) hay una incapacidad de los medios económicos para intervenir.

La primera razón es sencilla. Los medios económicos no sienten la necesidad de intervenir (al menos directamente y de manera forma) en el gobierno de las ciudades porque los medios políticos administran bien esos territorios. Tienen en cuenta las necesidades de las empresas - como las de otros actores- y garantizan el buen funcionamiento urbano (construcción de las infraestructuras necesarias, establecimiento de un mercado de empleo eficaz, etc.). Los casos pueden ser diversos. Así, la región de Île-de-France está dominada por el Estado que, a través de sus actuaciones, conforma el funcionamiento económico y social de la metrópolis, al menos hasta fechas recientes. Esto es lo que describen sobre todo los trabajos de H. SAVTTCH, en los que califica a la región de Île-de-France de régimen de tipo «planificador-dirigista» (CANTOR, SAVTTH y VICARI, 1997). El Estado garantiza el buen funcionamiento de la capital y no hay ninguna necesidad de que los actores económicos se impliquen, abiertamente o no, de manera organizada, en la medida en que un actor, el Estado, basta para permitir el desarrollo. Ésta es una de las razones invocadas por algunos autores (TRAVERS, 1997) para explicar el apoyo de los medios económicos londinenses a la Greater London Autbority y para explicar el mejor funcionamiento de la metrópolis parisina en relación con su rival londinense. De una forma un poco caricaturesca, el Estado francés se ocuparía de París mientras que el Estado británico no se ocuparía de Londres. Desde otro ángulo, es también el caso de la ciudad de Bolonia, donde la ósmosis entre los medios político y económicos bajo el cetro de la política (el Partido Comunista Italiano) permite a esta última administrar y desarrollar su territorio (JOUVE y LEFĖVRE, 1996). En ese modelo, los medios económicos son los instrumentos del poder político, de los que han surgido en buena medida (grandes cooperativas, bancos, establecimientos financieros, CCI, CNA).

La segunda explicación se refiere al mal estado de las relaciones entre los medios políticos y los económicos por diversas razones, especialmente ideológicas, que pueden remontarse muy lejos en la historia. Es el caso de ciudades como Lyon, Sheffield o Cardiff, donde la desconfianza entre los medios de negocios y los políticos ha impedido hasta hace poco una implicación de los primeros. Si Sheffield representa bien la lucha de clases (burguesía industrial frente a un proletariado que conquistó la Alcaldía), es distinto el caso de Lyon, donde la desconfianza entre la burguesía industrial y el ambiente político local no reposa en una base de lucha de clases, sino más bien en un concepto del reparto de las tareas entre la política y la economía. Sea cual sea, los medios económicos van a ver negativamente cualquier empresa política y van a rehusar a asociarse a ella, probablemente porque disocian el buen funcio- namiento de la aglomeración de la creación de una nueva institución, o incluso en alguno casos porque se oponen a ella. Es el caso en Bolonia de la ascendiente asociación de las empresas pequeñas y medianas (API), que ve en la Ciudad Metropolitana $(\mathrm{CM})$ una nueva estructura burocrática y que considera el proyecto de CM del Alcalde como un asunto propio del mundo político, es decir, una empresa que afecta al espacio y a la encarnación del poder político más que a la eficacia de las políticas públicas. A. Harding (1997) dice lo mismo de forma más extremada cuando afirma que los hombres de negocios desconfían de los esquemas institucionales, incluidos los que, como ocurre en el Reino Unido, se considera que desarrollan la implicación de las empresas. Más allá de las diferencias ideológicas, vemos surgir diferencias culturales sobre los papeles respectivos del político y del empresario.

La tercera razón de la no-implicación de los medios económicos tiene que ver con la escala de esta implicación más que con la implicación misma. El caso de Holanda ilustra plenamente esta situación. Es este país, los lazos entre medios económicos y políticos son estrechos, pero no se sitúan en el nivel local. En efecto, abordamos un sistema social basado en una diferenciación sectorial y funcional que excluye el territorio -lo que los holandeses denominan la «pilarización»-, en cuyo seno se desarrollan las relaciones entre la economía y la política. La implicación de los medios económicos se efectúa entonces en el nivel nacional, en el seno de los ministerios, y lo local, lo urbano, no es pertinente para influir sobre la política. En opinión de numerosos autores holandeses (TERHOST y VAN DE VEN, 1999; KREULES, 1999), este modelo de funcionamiento está en crisis y lo local aparece cada vez más como el lugar donde se realizarían las regulaciones. Deberíamos, pues, ver pronto una implicación de los medios económicos holandeses en el nivel local, al menos en los aspectos estratégicos, porque su presencia en el nivel urbano ha sido siempre significativa cuando se trata de proyectos sectoriales y de pequeña envergadura.

Una cuarta explicación reside en la misma estructura de los medios económicos y tiene en cuenta la fragmentación del mundo económico local como elemento clave de la no-implicación de los actores económicos. Son numerosas las ciudades que son ejemplo de este fenómeno, bien como estructura (Lyon, Milán, Berlín, Sheffield), bien como tendencia (Bolonia). Así, unos medios económicos fragmentados se mostrarían incapaces de desarrollar una visión estratégica a medio plazo relativamente homogénea, que justificase o sirviese de base a una intervención en el gobierno de la ciudad.

Finalmente, conviene señalar que estas cuatro razones para la no-implicación de los actores económicos no se excluyen entre sí. En la mayor parte de los casos esta no-implicación se explica por la concurrencia de varias de ellas. 


\section{La implicación de los actores económicos}

Una vez dicho esto, no es menos cierto que, en numerosos casos, los medos económicos se comprometen en los procesos de reformas institucionales. Su implicación adopta formas muy variadas, pero de una manera sencilla podemos distinguir dos tipos de compromiso. Un compromiso que se puede calificar de «pasivo» y un compromiso «activo». El compromiso «pasivo» corresponde a un llamamiento dirigido a los actores económicos por parte de los actores políticos; no son las empresas o sus asociaciones los iniciadores, sino más bien los poderes públicos. En cambio, el compromiso «activo» remite a situaciones en las que los medios económicos son los promotores de las reformas institucionales. Debe quedar claro que esta tipología es esencialmente didáctica en la media en que los actores políticos y los económicos pueden ponerse de acuerdo perfectamente sobre la necesidad de aplicar una reforma sin que sea realmente posible identificar quién es el principal y primer instigador.

\subsection{El llamamiento de la política a los actores económicos}

El reclamo de los actores económicos por parte de los poderes públicos responde a tres razones principales: una obligación legal (1), un estímulo relacionado con las políticas públicas (2) y una necesidad de hacer que la sociedad civil se incorpore a los proyectos políticos que son las reformas institucionales (3).

1) En algunos países las leyes obligan a los medios económicos a participar en estructuras cuya función es la de reflexionar sobre el funcionamiento de los territorios y especialmente de sus evoluciones institucionales. Dos ejemplos tomados respectivamente en Francia y en Gran Bretaña van a servirnos para ilustrar este tipo de situación.

En Francia las leyes descentralizadoras de comienzos de los años ochenta crearon una nueva entidad territorial: la región. La región está constituida por una asamblea ejecutiva, el consejo regional, y este consejo está asistido obligatoriamente por una segunda asamblea que agrupa a las fuerzas vivas del territorio: el consejo económico y social regional (CESR). En el seno de este consejo se encuentran los representantes del mundo social (sindicatos y medios asociativos) y del mundo económico (cámaras de comercio y organizaciones patronales). La ley establece de forma muy precisa los representantes de las empresas, su número y su proveniencia. Así, en el CESR de Île-de-France los medios económicos están representados por la Cámara de Comercio de París (CCIP), la Cámara de Comercio de Île-de-France (CRCI), la Cámara de Oficios y del Artesanado, así como la Cámara Agraria, en lo que respecta a los organismos corporativos; las empresas están representadas directamente también por sus organizaciones patronales, el Movimiento de
Empresas de Île-de-France (Medea Hile-de-Franje) para las grandes firmas, y la Confederación General de Pequeñas y Medianas Empresas (CGPME) para las empresas de esas dimensiones. Es en el seno del CESR, a través de su asamblea plenaria y sus comisiones sectoriales, como se expresan las reivindicaciones de los medios económicos ante los poderes públicos regionales. Constituye, pues, en la actualidad, el lugar donde algunos actores económicos, especialmente las grandes empresas, debaten el fortalecimiento de la institución regional frente al Estado y las demás entidades territoriales.

La Ley de Ordenación del Territorio de 1999 establece consejos de desarrollo para la mayor parte de las aglomeraciones francesas. Contrariamente a los CESR, la composición de los consejos de desarrollo se deja a las autoridades locales, pero la ley especifica sin embargo que los medios económicos deben estar representados. Estos consejos de desarrollo deben emitir su informe sobre los proyectos de aglomeración (documentos estratégicos que establecen las prioridades de las políticas públicas en la aglomeración) y estos proyectos de aglomeración van a servir de base para la creación de futuras instituciones que cubran el territorio metropolitano (Ley sobre la Cooperación Intermunicipal de 1999). Aún es demasiado pronto para analizar la implicación de los actores económicos en el seno de esas nuevas estructuras, porque las primeras han visto la luz a comienzos de año 2001, pero las empresas están presentes también aquí por medio de sus corporaciones y de las organizaciones patronales.

En Gran Bretaña el gobierno laborista se ha lanzado a una política de regionalización desde su llegada al poder. Sobre todo han creado agencias regionales de desarrollo (Regional Development Agencies o RDAs) y asambleas regionales (Regional Chambers). Estos dos órganos creados por una Ley de 1998 son de derecho estructuras mixtas en las que los actores económicos políticos (los representantes de las entidades territoriales) se codean con los actores económicos (los representantes de las empresas) y las otras fuerzas vivas (especialmente los medios asociativos y educativos). En el caso de las RDAs, los actores económicos incluso son mayoritarios y pilotan las nuevas estructuras. Son nombrados por el gobierno, que selecciona así a sus interlocutores.

Los actores económicos implicados en sus nueva estructuras son de naturaleza diversa, pero excluyen las formas organizadas. Así, no hay representantes de las cámaras de comercio ni de las organizaciones patronales como la Confederation of Business Industry (CBI), aunque es evidente que algunos miembros de los consejos de administración de las RDAs tienen tenues lazos con las organizaciones patronales. Se encuentran jefes de empresas de diverso tamaño, de envergadura internacional (British Airways, Pirelli) o simplemente local, en numerosos sectores de actividad (nueva economía, industrias tradicionales, comercio, etc.). Su implicación es efectiva, y aunque se explique por 
el campo de competencias de las RDAs (especialmente el desarrollo económico), sería erróneo pararse en esta constatación, en la medida en que su participación es igualmente efectiva en las asambleas regionales que prefiguran las futuras autoridades regionales que algunos miembros del gobierno y amplias partes de la sociedad británica reclaman.

2) Los gobiernos, sean nacionales, locales o incluso el europeo, impulsan cada vez más a los actores económicos a participar en las políticas públicas, no sólo en el nivel de su aplicación, sino también en el de su elaboración. En el caso de la Unión Europea o en algunos países (Reino Unido, Italia), se trata incluso de una cuasi obligación si las entidades locales desean financiación proveniente de otros niveles de gobierno, lo que ocurre cada vez más. No se trata aquí de una implicación obligatoria de los actores económicos en las estructuras políticas (como los CESR o las RDAs), sino en unas estructuras dirigidas a la aplicación de acciones específicas y todavía claramente sectoriales. Sin embargo, la evolución de las políticas públicas hacia formas cada vez más integradas e intersectoriales en territorios cada vez más amplios hace aparecer las estructuras que las pilotan como nuevos territorios políticos en gestación. El ejemplo de algunos pactos territoriales italianos es ilustrativo de tal evolución.

Creados a iniciativa del Ministerio de Tesoro hacia mediados de los años noventa, los pactos territoriales (PT) son procesos que reúnen de manera formalizada a los actores económicos, sociales y políticos. Las políticas afectadas por los PT se refieren al desarrollo del territorio desde una perspectiva intersectorial (desarrollo económico, medio ambiente, empleo y formación, infraestructuras, cohesión social) sobre territorios «pertinentes». Se trata casi siempre de territorios amplios, que cubren decenas de municipios, e incluso varias provincias, en los que se van a aplicar políticas pensadas a medio y largo plazo. Por el momento, esos territorios carecen de contenido político (en el sentido de que no se trata de la creación de nuevas instituciones), pero para algunos pueden prefigurar formas de mesogobierno. Los PT son dirigidos por estructuras mixtas, las «mesas técnicas», donde las entidades locales se codean con los representantes de los sindicatos de asalariados, las cámaras de comercio y las organizaciones patronales. Las empresas raramente son participantes e intervienen, pues, por medio de sus organizaciones. Todos juntos definen las orientaciones del desarrollo del territorio afectado, a partir de las cuales se elaborarán las políticas y las acciones sectoriales que hay que aplicar, en la medida en que la firma de un pacto territorial comprometa a los diversos socios.

La implicación de los actores económicos en estas formas organizadas de acción colectiva con fines estratégicos (que las acercan, pues, fuertemente a instituciones stricto sensu) se explica por la evolución económica y social de los territorios donde algunas empresas y algunas de sus asociaciones comienzan a darse cuenta de que tienen que jugar un papel activo en su organización territorial, en la media en que la calidad de esta organización aparece hoy en día como una ventaja comparativa en la competencia nacional e internacional. Pero incluso en estos casos no todas las empresas se sienten afectadas y no todas se implican.

3) En algunas metrópolis (Lyon, Londres, Bolonia, Roma) los proyectos de reformas de las instituciones metropolitanas han visto llamamientos explícitos hacia los medios económicos, realizados por los electos que los desarrollaban. En Bolonia, W. Vitali creó en 1997 una conferencia económica metropolitana, verdaderamente dependiente del órgano político ya existente que era la conferencia metropolitana. En Lyon, en los años noventa, también el Alcalde $M$. Noir intentó implicar a las empresas en su proyecto de región urbana. En Londres, el gobierno laborista consultó a los hombres de negocios sobre el proyecto de creación de la Greater London Autbority (GLA). La respuesta de los medios económicos no fue unívoca.

En Londres, las empresas han respondido más bien favorablemente (véase la sección siguiente), pero con diversas impli. caciones. Mientras que algunas grandes firmas se movilizaron fuertemente, la Cámara de Comercio o la CBI se mostraron más prudentes (KLEINMAN, 1999). En Bolonia o en Lyon, los actores económicos han manifestado más bien una relativa hostilidad y han preferido distanciarse de los proyectos institucionales que consideraban bien inútiles, bien dependientes estrictamente de estrategias políticas que no les afectaban. En Bolonia, la Conferencia Económica metropolitana no ha funcionado, al enviar las empresas y sus asociaciones representantes sin poderes reales. El proyecto de ciudad metropolitana se ha considerado ampliamente como un proyecto puramente político, al servicio de un hombre (Jouve y Lefèvre, 1999b). Además, las PYMEs han manifestado, por medio de su organización, la API (Associazione delle Piccole Imprese), su temor de que la futura institución se convierta en una estructura político-administrativa más, añadiendo así más burocracia a la existente. El Alcalde de Bolonia no logró convencer de la bondad de la nueva institución, uno de cuyos objetivos avanzados era, sin embargo, la simplificación de los procedimientos administrativos. Además, estas empresas fueron bien apoyadas en el nivel municipal por el City Manager de Bolonia, declarando sin ambages que la metrópoli emiliana tenía prioridades más importantes que la creación de la ciudad metropolitana.

En Lyon (Ben Mabrouk y Jouve, 1999), ADERLY, la asociación de las empresas de la región lionesa, rechazó implicarse en los proyectos de desarrollo del Alcalde de Lyon y rechazó garantizar la transformación de la región urbana en una institución política. Más recientemente, el lanzamiento del Plan Director de Desarrollo Económico por el nuevo Alcalde, R. Barre, sólo suscitó poco interés por parte de los medios económicos, que se contentaron con una ligera participación. 


\subsection{Los actores económicos llaman a la politica}

La interpelación de los poderes públicos por los medios económicos en favor de las reformas institucionales de los territorios se realiza sin duda alguna cuando el funcionamiento institucional de esos territorios se revela defectuoso. Esto puede suceder en dos casos típicos: bien en una situación de crisis, es decir, cuando se asiste a una incapacidad de las autoridades públicas para responder a problemas cuya solución es urgente (1), bien en una situación de disfuncionamiento menos urgente pero que los actores económicos identifican como estructural y que se traduce principalmente en la necesidad de una mejora de la acción conjunta de las entidades territoriales (2).

1) En algunas metrópolis y en algunos períodos, la incapacidad de las autoridades políticas frente a cuestiones candentes ha podido precipitar la acción de los medios económicos a favor de reformas institucionales significativas, al considerarse insuficientes una «medidas a medias» para responder a la urgencia de los problemas. Incluso en esos casos nunca asistimos a una intervención global del conjunto de los actores económicos, sino, por el contrario, según los retos, a una implicación específica de algunos de ellos.

En Milán, en los años ochenta y noventa, las grandes empresas (Italtel, Pirelli, grandes bancos, Montedison, etc.) se agruparon en una asociación ad boc, la Assosiazione degli Interessi Metropolitani (AIM), cuyo objetivo principal ha sido hacer tomar conciencia de la necesidad de constituir un gobierno metropolitano. Esta nueva institución o este nuevo acuerdo institucional habría permitido responder a insuficiencias en el funcionamiento del territorio consideradas cruciales por esas grandes empresas; ausencia de cobertura eficiente de la aglomeración por los transportes colectivos o las redes de carreteras, necesidad de construcción de un nuevo aeropuerto internacional, necesidad de concretar algunos proyectos de grandes actuaciones: nueva universidad, ampliación de la feria, etc. La AIM se ha movilizado fuertemente durante prácticamente diez años, pero se ha enfrentado a una incapacidad crónica de las instituciones políticas para tener en cuenta la cuestión metropolitana, y ello a pesar de las leyes nacionales que le eran favorables (especialmente la Ley 142 de 1990). La cuestión metropolitana necesitaba -y necesita aún en Milán- una cooperación entre el municipio central, la provincia y la región, pero estas tres entidades siempre han sido rivales. Ante la incapacidad de las autoridades políticas, la AIM se centró poco a poco en otras preocupaciones (nuevas tecnologías, formación profesional, mejora del medio ambiente), pero no fue emplazada por otras estructuras (FARERI, 1998; MinOTTI, 1998).

Más o menos los mismos problemas son los que produjeron la intervención de los medios económicos en Londres a comienzos de los años noventa. Frente a la caída de los precios del suelo y a la degradación de las condiciones de transporte y de accesibilidad de la capital británica, y ante el inmovilismo del gobierno y la incapacidad de acción de las entidades locales [después de la disolución del Greater London Council (GLC) en 1987], las grandes empresas constituyeron una asociación, London First, cuyo principal objetivo ha sido el de ejercer presión sobre èl gobierno para que se ocupe más de la capital. Es en el marco de London First donde se gestó entre los actores económicos la idea de la importancia de una estructura política que cubriese el territorio del Gran Londres, aunque también fuese prioritaria para la oposición laborista.

En Stuttgart, es la crisis fiscal de la ciudad central -habiendo sonado varias veces la señal de alarma ante su creciente incapacidad para asumir sus «cargas de centralidad»- la que precipitó a comienzos de los años noventa la intervención de la Cámara de Comercio, sostenida por algunas grandes empresas, que ha favorecido de esta forma la creación de la Verband Regio Stuttgart (VRS), única estructura política de envergadura metropolitana en la Alemania actual.

En Burdeos, es el final de reinado del «Sistema Chaban» ${ }^{3}$, incapaz de redinamizar la capital de Aquitania y de responder mediante políticas públicas a las demandas de las empresas (numerosos proyectos de ordenación en espera, construcción del metro paralizada), lo que ha precipitado la intervención de la Cámara a favor de la creación de un Gran Burdeos, proyecto de creación de una estructura metropolitana que cubra la ciudad central y la primera corona de la periferia. La renovación de una parte de la élite política local con la llegada en 1995 de un nuevo Alcalde, Alain Juppé, entonces Primer Ministro, cambió este contexto, mostrándose este último capaz de orientar hacia Burdeos recursos nacionales (especialmente las Administraciones nacionales deslocalizadas), lo que hizo decir en la época al Presidente de la CCI que «con el Sr. Juppé, Burdeos puede pasar de una reforma institucional» (FRENZEL, 2001).

2) Pero la implicación de los medios económicos en las reformas institucionales no debería reducirse a las situaciones de crisis. La idea, verdadera o falsa, de la importancia de una buena organización institucional del territorio como ventaja comparativa en la competencia internacional que libran las ciudades entre sí (GORDON y CHESHIRE, 1996) se ha abierto camino en los medios económicos. Nos encontramos aquí con situaciones en las que las reformas institucionales son vistas por algunos actores económicos como elementos estratégicos. No se trata, como en el caso precedente, de desear reformas institucionales en el nivel metropolitano para producir bienes y servicios o para paliar disfuncionalidades importantes y urgentes del territorio, una vez han sido localizadas de antemano. Se trata, de manera más imprecisa, más incierta, de actuar para la construcción de un sistema institucional menos costoso en transacciones, más sencillo, más claro y globalmente más eficaz, 
sin que se sepa muy bien cómo medir esta eficacia. Tres ejemplos van a ilustrar esta finalidad.

La creación del Greater London Autbority (GLA) corresponde en su forma y en su contenido al deseo de las empresas (KLENMAN, 1999). El periodo comprendido entre 1987, fecha de la abolición del GLC, y el 2000, fecha de la creación de la GLA, estuvo marcado por importantes disfuncionalidades en la producción de políticas públicas y en la capacidad de los actores locales, especialmente las entidades locales, para producir una acción conjunta. El elemento emblemático de estas disfuncionalidades ha sido la incapacidad del Gran Londres para producir una candidatura coherente para los Juegos Olímpicos de 2004, ya que vieron la luz dos proyectos londinenses competidores entre sí. Esta situación fue considerada por la mayor parte de los actores locales como el resultado de la fragmentación política de Londres, donde ningún proyecto se encontraba en condiciones de ganar y donde ninguna estructura disponía de la legitimidad necesaria para imponer uno. Desde entonces se gestó la idea de (re)crear un órgano que pudiese hablar y decidir por el conjunto del Gran Londres, «A voice for London». Los actores económicos se encontraron entre los principales promotores de esta idea, que se concretó poco a poco en la creación de la GLA. En 1998 se creó el London Development Partnership (LDP), partenariado público-privado de carácter estratégico, dirigido a generar una reflexión sobre el futuro del Gran Londres y sobre sus orientaciones y las prioridades en materia de desarrollo económico y social. Aquí también fueron las grandes empresas (el Presidente de LDP era el PDG de British Airways) las que por medio de London First crearon esta nueva estructura. La LDP apoyó fuertemente la creación de la GLA porque, según él, Londres necesitaba hablar con una sola voz para hacerse oír por el gobierno central y por la Unión Europea, y para poder generar políticas coherentes que garanticen su competitividad en el nivel mundial.

El caso parisino es del mismo tipo. Al contrario que Londres, Île-de-France dispone de un actor que desde hace tiempo ha administrado sin compartir (CEBR, OEIL, 1997): el Estado. Pero este último ha gestionado la capital de Francia según sus propias lógicas. La llegada de la descentralización y la creación de una institución regional, el Consejo de Île-de-France (CRIF), han cambiado poco esa situación. Hoy en día, el CRIF aspira a ensanchar su campo de competencias y pide nuevos recursos, lo que se hará en su momento en detrimento del Estado o incluso de otras entidades territoriales. Falta que el territorio de la competencia del CRIL coincida bastante bien con el de la región funcional. En el contexto parisino, el fortalecimiento del nivel regional aparece como una reforma institucional metropolitana. La posición de los actores económicos frente a este proceso no es unívoco, pero en el conjunto es más bien favorable, sobre todo en el caso de las grandes empresas representadas por el MEDEF (Movimiento de las Empresas de Fran- cia). La razón parece simple. En un mundo globalizado en el que la competencia entre los territorios se acentúa, ćqué institución parece más adecuada para representar los intereses de la metrópolis, el Estado o la región? Algunos actores económicos se han manifestado en favor de la región y, por lo tanto, en favor de un fortalecimiento de su papel con la siguiente argumentación: la región intenta esencialmente desarrollar su territorio, mientras que el Estado tiene más bien una visión nacional en la que el equilibrio entre las regiones debe mantenerse. El Estado francés ha tenido siempre una política de reequilibrio a favor de la provincia (la Francia fuera de París) y ha «sancionado» a la capital mediante sus políticas de ordenación del territorio. Así, la región de Île-de-France no ha podido beneficiarse de los fondos estructurales europeos como consecuencia de su poder económico desmesurado en relación con el resto de la nación. El Estado ha buscado y busca aún deslocalizar algunas de sus Administraciones en la provincia. Para los medios económicos establecidos en Île-de-France para los que no es admisible abandonar ese territorio, sea cual sea el tamaño de la empresa considerada, es importante, pues, fortalecer el nivel regional, porque este último sirve «objetivamente» sus intereses.

La situación de la capital italiana, Roma, es algo diferente. Parece que hay un apoyo casi unánime de los medios económicos a la creación de la Ciudad Metropolitana, porque esta institución se considera como la única alternativa creíble a la fragmentación institucional existente (D'AlBERGO, 2000). En efecto, en Roma el Estado nunca ha jugado el papel que ha podido desarrollar en Île-de-France, e incluso, aunque en una medida inferior, que en Londres. Muy a menudo la acción pública se ha encontrado paralizada debido a la falta de coordinación entre la región del Lacio, la provincia y la ciudad central de Roma. Los medios económicos están cansados de las querellas entre esos niveles institucionales que durante mucho tiempo han tenido como resultado el inmovilismo. Para remediarlo, las entidades locales italianas se han lanzado, con el apoyo del Estado, a una multiplicación de los procedimientos de cooperación, de negociación y de contractualización, generalmente sectoriales, en los que se han implicado los actores económicos. Esta multiplicación de los procedimientos se ha traducido en un incremento de los costes de transacción, sin que resulten convincentes los resultados en términos de políticas producidas. Frente a esta situación, la mayor parte de los actores económicos se declaran favorables a la creación de una Ciudad Metropolitana porque ello permitiría una importante reducción de estos costes de transacción mediante la creación de una especie de ventanilla única, una simplificación significativa del sistema decisional.

Mientras que en el caso londinense son los medios económicos los que se han mostrado más activos en la creación de una institución metropolitana nueva, en el caso parisino y 
romano, su implicación es menos directa. No son los iniciadores, pero participan, algunos de forma muy activa, en lo diversos procedimientos contractuales organizados por la región de Île-de-France o las entidades locales del Lacio y en las estructuras de concertación que se desarrollan entre las instancias políticas y las fuerzas vivas de los territorios, dando así una mayor legitimidad a las instituciones promotoras de las reformas, la región de Île-de-France y el municipio central en el caso de la aglomeración de Roma.

\subsection{La lógica de la reforma}

La implicación de los medios económicos en las reformas institucionales se desvela también a la vez como más nítida y menos directa en la evolución de la organización misma de las estructuras de representación de las empresas. P SCHMITTER y L. LANZALACO (1989) distinguen en sus trabajos dos tipos de lógica que explican las formas de organización territorial de los intereses económicos: la lógica de pertenencia y la lógica de influencia. La lógica de pertenencia reenvía a la composición misma de las empresas que se asocian; las formas territoriales de organización económica dependen, pues, del tipo de empresas (tamaño, sector de actividad, autonomía) existentes en un territorio determinado. La lógica de la influencia reenvía a las relaciones entre los actores económicos y su entorno, especialmente su entorno político-administrativo. Por lo tanto, es esta lógica de influencia la que nos interesa más especialmente aquí.

Según esta lógica, los actores económicos van a tener tendencia a organizarse sobre territorios que van a facilitar las relaciones con los actores políticos, especialmente con el fin de influir sobre las políticas públicas. En ese marco, la evolución de la organización territorial de las asociaciones de empresas (órganos tradicionales de representación, estructuras ad boc) puede decirnos mucho sobre la institución privilegiada por los medios económicos en sus relaciones con la política. Algunos ejemplos no permitirán ilustrar esta idea.

Desde enero de 2001, las cámaras de comercio y de industria de Hile-de-Franje han decidido fusionarse para crear una nueva CCI de nivel regional cuyo territorio coincide naturalmente con el de la entidad regional. Esta evolución es significativa, en la medida en que se trata de un reconocimiento por parte de los actores económicos del nivel regional como nivel político administrativo que hay que privilegiar en el futuro. Ellas desean de esta forma tener más peso con respecto al Estado (que también está desconcentrado en el nivel regional) y unificar sus fuerzas frente al aumento de poder de la entidad regional. Esto no significa para nada que las CCI deseen este fortalecimiento de la región, pero su reorganización sobre esta base regional conforta de forma evidente a la instancia regional frente a los demás actores políticos.
El caso británico ilustra de forma inversa esta situación. La regionalización política en curso en Inglaterra se basa parcial. mente en una regionalización efectiva de algunos actores económicos. Así, en el Noroeste de Inglaterra, algunos actores económicos se han constituido a comienzos de los años noventa en asociaciones regionales como la Nortb-West Business Leadersbip Team (HeBberT, 1999), prefiguración parcial de la actuales RDAs. La creación a mediados de los años noventa de London First y después de London Development Partnership sobre el territorio del excondado metropolitano demuestra también que el territorio del Gran Londres se revelaba pertinente para estos actores y, por lo tanto, que una reforma institucional sobre esta base recibiría el apoyo de los medios económicos.

\section{Las RIM, ejemplo de una acción colectiva incierta}

El análisis que hacemos de las reformas institucionales en las áreas metropolitanas a través del estudio de la evolución de las relaciones entre actores políticos y actores económicos es un buen ejemplo de las dificultades para desarrollar políticas públicas en la actualidad y, por lo tanto, de gobernar los territorios. En efecto, finalizamos el análisis con la imagen de una sociedad metropolitana fragmentada, tanto en lo que se refiere a los actores políticos como a los medios económicos, donde la capacidad de dar coherencia, coordinar, regular y sobre todo de dirigir el desarrollo de las metrópolis es cuestionada de forma especial. A partir de esta situación, vamos a centrarnos en la conclusión de este artículo, presentando en primer lugar la fragmentación política de las aglomeraciones, luego la de los actores económicos, para cuestionar en tercer lugar la gobernabilidad de los territorios urbanos.

\section{La fragmentación política de las metrópolis}

La fragmentación política de las metrópolis es el resultado, aún inacabado, de un doble proceso que vincula la reconfiguración del papel del Estado y el incremento del poder del nivel local debido a la evolución descentralizadora y federalista de algunos países europeos.

Si ha sido excesivo o apresurado hablar de una retirada del Estado, como destacan WRIGHT y CASSESE (1997), hay en la actualidad una recomposición del Estado, es decir, una transformación de su papel en el gobierno de los territorios. Transformación de su papel no significa sin embargo que se sepa 
claramente hacia dónde evoluciona y las vías pueden ser muy diferentes según los países, entre la vía federalista italiana, el regionalismo funcional holandés (KREUKELS, 1999) o británico (Cabinet Office, 2000).

Sea lo que sea, recomposición del Estado significa pérdida de una dirección central de la acción pública desde lo alto. No es pensable que se vuelva a medio plazo a un Estado de tipo jacobino o que monopolice la legitimidad política. Esta trasformación del papel del Estado se encuentra en las metrópolis y quizás principalmente en aquellas donde habría tenido más tendencia a invertir: las capitales.

En Londres, como consecuencia de la abolición del Greater London Council (GLC), el Estado sustituyó progresivamente a este último para asumir algunas competencia como los transportes. Sin embargo, la concepción neoliberal del gobierno británico de la época, no cuestionada en lo esencial por el gobierno laborista, ha jugado en contra de una reconquista de la capital británica por el Estado. Hemos visto cómo se movilizaron las grandes empresas frente a cierto abandono de Londres por el Estado británico, y especialmente en sus políticas de transporte. La desaparición del GLC no fue compensada, pues, por una dirección central del Estado. Por el contrario, la capital se ha encontrado fragmentada entre 33 borougbs, por una parte, y por otra una miríada de partenariados público-privados (véase sección III.3), sin que el Estado llegue a jugar un papel de coordinador sobre el territorio londinense.

En Île-de-France la situación ha seguido la misma evolución en muchos aspectos. El Estado ha perdido en buena medida su capacidad de acción, financiera, de asesoramiento y política. No es capaz de jugar, como antes, un papel de piloto de la región parisina y ya no está capacitado para cumplir una función de coordinador y de animador. En el mejor caso, puede intentar a través de sus políticas constitutivas, especialmente las referentes a la «intermunicipalidad», tratar de estructurar la acción de las entidades locales. Hoy en día, la región parisina no tiene un verdadero director y si bien el Estado continúa jugando un importante papel, debe transigir con una institución en ascenso, la región, con unos departamentos fortalecidos por la descentralización y con los municipios (alrededor de 1.200) que comienzan desde 1999 a agruparse en torno a proyectos de naturaleza política, como el desarrollo económico y la ordenación del territorio.

Esta pérdida de dirección central de la metrópoli está siendo compensada por algunas entidades locales que se han visto fortalecidas por las políticas de descentralización y de federalización. En Italia, son las regiones, verdaderas ganadoras de la evolución federalista de la península, las que han visto fortalecidas sus competencias. Aún es demasiado pronto para saber cómo van a comportarse en las metrópolis y si van a poder garantizar la coherencia de las políticas públicas, al menos en algunos sectores. Es posible que el federalismo italiano sea un federalismo de varias velocidades con regiones poderosas $\mathrm{e}$ intervencionistas y otras menos ricas en recursos de todas clases y menos intervencionistas. El caso milanés demuestra una región, Lombardia, que presenta tendencias centralizadoras frente a las demás entidades locales (provincias y municipios), pero las últimas leyes de descentralización han fortalecido a estas últimas. De todo ello se deduce un panorama fragmentado donde la región, la provincia de Milán y la ciudad central se encuentran hoy día frente a frente.

En Londres, la descentralización ha permitido la creación del Greater London Autbority, pero esta nueva institución tendrá dificultades para jugar el papel de coordinador, y a fortiori el de piloto que deseaban algunos actores locales. En efecto, las competencias de la GLA son bastante menores que las de la antigua GLC (KLEINMAN, 1999). Esto se ve en su presupuesto y en la importancia de su personal, diez veces menor que el del Greater London Council. Además, el Estado está muy presente con su órgano desconcentrado, el Government Office for London, en plena reestructuración a fin de conferirle un papel más adecuado a la evolución político-institucional de la capital.

En Île-de France, la situación es similar, con una región que fortalece sus poderes (con una posible transferencia competencial en materia de trasportes, de educación y de salud) y sus instrumentos de control del territorio (reciente creación de una Agencia Regional de Desarrollo; participación en la estructura de gestión de los transportes públicos, el Consorcio de Transportes de Île-de-France, desde el 2001). Sin embargo, todo se conjura para impedir que el Consejo Regional se convierta en el nuevo piloto de la metrópoli parisina: la continuación de la presencia del Estado, que en algunos sectores continúa siendo el actor principal; el desarrollo de los departa. mentos; el incremento del poder de las estructuras intermunicipales por la vía de las comunidades de aglomeración surgidas de la Ley de 1999.

Esta fragmentación política de las metrópolis puede conducir a confrontaciones entre entidades territoriales que las reformas institucionales pueden agravar. Así, en Milán, el debate sobre la Ciudad Metropolitana se ha malogrado porque uno de los elementos de la reforma era la fragmentación de la ciudad central de Milán en varios municipios. La misma provincia de Milán hizo una propuesta de división en 20 municipios a comienzos de los años noventa, lo que fue rechazado por la ciudad central. Por su parte, la región no vio con buenos ojos que la provincia se erigiera en futura Ciudad Metropolitana por el hecho de que su territorio coincidiese más o menos con el área funcional milanesa. En Roma, la confrontación entre la región, la provincia y el municipio central ha sucedido a los primeros intentos de cooperación entre esas entidades territoriales, que incluso habían creado en 1999 varias oficinas metropolitanas comunes. Este proceso fue paralizado como 
consecuencia de las elecciones provinciales y regionales en las que los partidos de la oposición de derecha reconquistaron esos dos niveles políticos, quedando solamente el municipio de Roma en manos de la izquierda. Hoy día, ante la incapacidad de las estructuras locales para ponerse de acuerdo en una reforma institucional coherente, la ciudad de Roma intenta arrancar del Estado un estatuto especial, de tipo distrito federal, como el existente en las ciudades de Washington o Méjico (Commune di Roma, 2000).

En Île-de-France el incremento de poder de la institución regional es mal percibida por la ciudad departamento de París, que continúa siendo por el momento la entidad local más fuerte, con un presupuesto de cerca de 40.000 millones de francos (cerca de 6.000 millones de euros), frente a un presupuesto tres veces menor de la región. Pero la ciudad de París no es la única que teme el desarrollo del poder regional; los demás departamentos también en ese proceso que podrían acabar viendo a la instancia regional ocupando una posición de supremacía en un sistema institucional refundado.

En los países federales (Suiza, Alemania) el incremento del poder del hecho metropolitano provoca una especie de rebelión de las ciudades centrales frente a los sistemas institucionales, acusados de favorecer los intereses rurales. Así, la ciudad de Zurich pide la creación de un cantón urbano en el nivel de la aglomeración, lo que supondría una división del cantón actual. En Baden-Wurtemberg, la constitución de la Verband Regio Stuttgart, aunque realizada con el apoyo del Land, bien podría acabar en una confrontación entre ambas instituciones cuando la VRS comience a tener estrategias disconformes con los deseos del Estado federado.

\section{La fragmentación de los actores económicos en las metrópolis}

El proceso de fragmentación de los actores económicos en los territorios metropolitanos no está probado en la actualidad. Por el momento no se ha realizado ningún trabajo comparativo de una amplitud significativa. La fragmentación de los medios económicos es, pues, una hipótesis que avanzamos y que hemos tratado de basar en cuatro elementos: 1) un crecimiento de la hetereogeneidad de las empresas presentes en el territorio urbano; 2) una crisis de representatividad de las organizaciones tradicionales de firmas; 3) un proceso de contestación de estas organizaciones, y 4) la creación de nuevas formas de organización de empresas.

a) El paso de los sistemas económicos de tipo fordista a lo que, a falta de una expresión mejor, se califica en la actualidad de postfordismo, se caracteriza de forma evidente por profundas transformaciones en el interior del sistema productivo metropolitano, aunque no sea posible incluir el conjunto de ciudades europeas en un solo modelo. Para nuestros fines, la creciente hetereogeneidad de los sistemas productivos locales se caracteriza por el creciente poder de las PYMEs, que ocupan así un lugar cada vez más significativo en la economía local, y por la emergencia de nuevos sectores de actividades (NTIC, nueva economía, biotecnología, etc.). Esta evolución no encuentra ventajas en las formas tradicionales de representación de las empresas, que continúan estando muy marcadas por el período fordista, no tanto por el hecho de la evolución del tamaño de las empresas como por el de que los nuevos sectores de actividad están poco representados en ellas.

b) En todas partes, pero con diversos grados, las organizaciones tradicionales de representación de las empresas sufren una crisis de representatividad. A la vista de los diferentes estatutos (organizaciones voluntarias como el Reino Unido u organismos públicos como en Francia o en Italia, por ejemplo) y funciones (las funciones que desarrollan ante sus miembros, pero también los ámbitos en los que intervienen), es difícil comparar y medir esta crisis con rigor. Esta crisis se manifiesta por una disminución de la participación en las elecciones de esas estructuras (en Francia en las últimas elecciones de las CCI en noviembre de 2000 la participación cayó hasta el 12 por 100 aproximadamente en el nivel nacional y menos del 8 por 100 en la región parisina) y por una bajada de número de socios de las organizaciones filiales, aunque es evidente que este descenso varía según los sectores de actividades, los territorios y los países.

c) Se comprende mejor en este contexto el rechazo de esas organizaciones tradicionales. Por un lado, las empresas muy grandes, de envergadura internacional, no pasan por esas estructuras para ser representadas, pero esto no es nuevo porque siempre han tenido los medios para incidir en la política sin recurrir a ellas. Por otro lado, algunos sindicatos patronales locales como algunos MEDEF territoriales en Francia destacan claramente que son ellos los que representan al mundo de la empresa frente a las CCI, que sólo se representan a sí mismas o a las PYMEs menos innovadoras y menos creadoras de empleo. Finalmente, las nuevas empresas o las que han invertido en nuevos sectores de actividades consideran que las misiones cumplidas por las CCI o las uniones patronales por ramas ya no se adaptan a sus necesidades. Prefieren agruparse según otros criterios.

d) Vemos aparecer, en efecto, en las metrópolis europeas nuevas formas de agrupación y organización de las empresas. Éstas formas pueden variar según los países o las ciudades, pero todas tienen un punto en común: llevan consigo una contestación de las estructuras tradicionales existentes en dos elementos fundamentales: el territorio y el sector de actividad.

En el plano territorial, se observa, en efecto, una multiplicación de las estructuras de representación de las empresas que cubren otros espacios que los «poseídos» por las organizaciones tradicionales. Así, en Milán, mientras que la Cámara de Comer- 
cio y las principales asociaciones de empresas como Assolombarda se organizan en el nivel provincial, otras se agrupan en niveles más pequeños, cubriendo varios municipios como las asociaciones de empresas creadas en torno a la Agencia de Desarrollo del Norte de Milán (ADNM). En Manchester se han creado varios niveles territoriales de agrupación de empresas (entre ellos un nivel regional con el North.West Business Leadership Forum y un nivel metropolitano con Marketing Manchester), encontrándose, por otra parte, algunas firmas en varias de esas estructuras (HeBbERT, 1999). En la región de Île-de-France se crean asociaciones de empresas en territorios que podemos calificar de nivel meso y que cubren las nuevas estructuras intermunicipales, mientras que tradicionalmente las firmas están representadas en organismos de nivel departamental o municipal.

Las nuevas estructuras que se crean cuestionan la división por ramas o por sectores de las agrupaciones tradicionales. Así, London First ha reunido empresas cuya base de agrupación no era el sector de actividad, sino más bien objetivos comunes a las grandes empresas. Ése es también el caso de la AIM en Milán. En Lyon la Agrupación Industrial Lionesa (GIL) ha visto cuestionada su hegemonía por la aparición de nuevas estructuras basadas en intereses comunes que no son sectoriales.

\section{La gobernabilidad metropolitana en cuestión}

Las metrópolis europeas se encuentran afectadas en la actualidad por procesos de fragmentación de los actores políticos y de los medios económicos. Los canales de mediación tradicionales que se han forjado sobre bases antiguas, como el corporativismo a través del cual las autoridades políticas definen y seleccionan sus interlocutores económicos, tienen cada vez más problemas para funcionar, es decir, para asumir una capacidad legítima de producción y aplicación de políticas públicas. A falta de algo mejor, algunas entidades locales buscan mantener esos canales $-\mathrm{y}$, por lo tanto, las estructuras subyacentes- ayudándolas a perdurar. Así, en la región de Île-de-France algunos departamentos «subvencionan» a las organizaciones patronales porque necesitan interlocutores en los medios económicos.
La fragmentación de los actores se traduce en una multiplicación de los canales de mediación entre la esfera de la política y el mundo económico, ya que a los canales tradicionales vienen a añadirse otros nuevos, menos estables, sobre bases territoriales diferentes, más intersectoriales quizás. El leitmotiv del partenariado público-privado, considerado al comienzo como un instrumento de gestión de operaciones puntuales, entendido ahora como un sustituto de los canales de mediación tradicionales, no responde por el momento a la desagregación del sistema de actores, ya que, por el contrario, contribuye a dicho sistema, como lo demuestran todos los análisis del caso británico (HEBBERT, 1998; DeTR, 1999). Tanto de un lado como del otro, actores políticos y hombres de empresa intentan crear nuevos interlocutores o nuevas agencias de interlocutores.

Al lado de los actores políticos, son numerosos los intentos de constituir, fuera de las formas tradicionales de representación del mundo económico, partenariados estables y legítimos. En Île-de-France son algunos departamentos los que «juegan a entrometerse» para crear nuevas agrupaciones de empresas. Son también las nuevas fórmulas intermunicipales nacidas de las leyes de 1999 (comunidades de aglomeración) que tratan de constituir sobre sus territorios competenciales estructuras ad boc de firmas. En Milán, son la ASNM y los municipios que la dirigen los que «fabrican» un organismo, el foro de desarrollo (Diciommo, 2001). En Gran Bretaña, es el Estado el que produce sus propios interlocutores económicos, por un parte, con la creación de las Agencias Regionales de Desarrollo donde él mismo selecciona a los representantes de las empresas, por otra parte Londres con la legitimación del London Development Partnership y hoy día con la participación de las formas en la London Development Agency.

También los medios económicos pueden intentar construir sus interlocutores políticos. La reforma de las instituciones metropolitanas es un instrumento que pueden elegir porque su fin principal es precisamente cambiar el espacio del poder y constituirlo a una escala considerada más pertinente, cualesquiera que sean las razones invocadas para esta pertinencia. Pero desde esta perspectiva, hemos visto que los medios económicos se dividían y que, en suma, su papel no es determinante, con algunas excepciones, como en Londres, ni sobre todo determinante. 
* Este artículo ha sido traducido al español por José Manuel Rodriguez Álvarez, Subdirector General Adjunto de Cooperación y Régimen Jurídico Local (MAP) Profesor Asociado del Departamento de Ciencia Política y de la Administración de la Universidad Autónoma de Madrid y miembro del equipo internacional de investigación sobre «Nuevos territorios urbanos y actores económicos organizados», dirigido por el Profesor Lefivre y financiada por la European Science Foundation.

* Investigador del Laboratorio Técnicas, Territorios y Sociedad (LATTS). Profesor de la Universidad París 8. Profesor del Instituto francés de urbanismo.
${ }^{1}$ Así, en los paises anglosajones y escandinavos, un Estado democrático se caracteriza por contrapoderes territoriales importantes, mientras que en los paises de cultura latina y de sistema napoleónico no se reivindica la existencia de tales contrapoderes.

2 CCI: Cámaras de Comercio e Industria.

${ }^{3}$ Nota del traductor: Esta expresión hace referencia al largo reinado de Chaban Delmas, antiguo Primer Ministro, como Alcalde de la ciudad bordolesa.

\section{Bibliografía}

AMIN y THRIFT (1995), «Globalization, institutional "thickness" and the local economy», en P. HEALEY y otros (ed.), Managing cities: the new urban context, John Wiley: Chichester, GB

Bassolino, A. (1997), La Repubblica delle città, Roma: Donzeli.

Ben Mabrouk, T., y Jouve, B. (1999), «Lyon», en Jouve y LeFĖve (1999), Villes, Métropoles: les nouveaux territoires du politique, Paris: Anthropos.

BENNET, R. (1989) (bajo la dirección de), Territory and administration in Europe, Londres: Pinter.

Cabinet Office (2000), «Reaching out: the role of central government at regiona and local levels», Performance and Innovation Unit, Londres.

CEBR y OEIL (1997), «Two great cities: a comparison of the Economies of London and Paris», Londres: Informe para la Corporación de Londres.

Comune di Roma (2000), Conclusión del Coloquio «Città Metropolitana e attori socio-economici: Roma e le altre citta europpe», Roma, 15 diciembre de 2000

Cox, K., y MarR, A. (1988), «Locality and Community in the Politics of Local Economic Development».

D'A LBERGo, E. (2000), «Gli interessi socio-economici e il cambiamento istituzionale a Roma», communication au Colloque "Città Metropolitana e attor socio-economici: Roma e le altre citta europee», Roma, 15 de diciembre de 2000.

DETR (Department of the Environment, Transport and the Regions) (1999), «Area-based and other regeneration-related initiatives: Action research support for the co-ordination of area based initiatives», Londres: DETR

Diciommo, F. (2001), «The Economic actors and city governability: the example of urban regeneration policies in Milan, Naples and Paris», communicación a la conferencia «Area-based initiatives in contemporary urban policy», Copenhague: Eura, 17-19 mayo.

FARERI, P. (1997), «Acteurs et politiques urbaines à Milan», Pouvoirs Locaux, 33,2

Frenzel, A. (2001), Bordeaux, en Jouve, B., y LefÈre, C. (2001), In search of Urban Gargantuas: Power and Territoires in European metropolises, Londres: Franck Cass.

- (2001), Stuttgart, en Jouve, B., y Lefèvre, C. (2001), In search of Urban Gargantuas: Power and Territoires in European metropolises, Londres: Franck Cass.

GORDON, I., y CHESHIRE, P. (1996), «Territorial competition and the predictability of collective (in)action», International Joumal of Urban and Regional Research.

GuY-Peters, B. (1997), «With a little help from our friends: Public-private partnerships as institutions and instruments», en PIERRE, J. (1997), Partnerships in urban governance: European and American Experience, Londres: MacMillan.
Harding, A. (1997), «Urban Regimes in a Europe of Cities?», European Urban and Regional Studies, 4, 4: 291-314.

HebBert, M. (1999), «Villes, Métropole ou région? Les territoires de la mobilisation à Manchester», en Jouvve, B., y Lefìve, C. (1999), Villes, Métropoles. les nouveaux territoires du politique, Paris: Economica, Anthropos.

- (1998), London: more by fortune than design, Londres: Wiley.

Jouve, B., y LeFĖvre, C. (2001), In search of Urban Gargantuas: Power and Territoires in European Metropolises, Londres: Franck Cass. (Versión inglesa de Jouve y LEFĖVRE, 1999.)

- (1999) (bajo la dirección de), Villes, Métropoles: les nouveaux territoires du politique, París: Anthropos.

- (1999b), «La cité métropolitaine de Bologne: de la première à la seconde république?», en Jouve y LEFĖVRE (1999) (bajo la dirección de), Villes, Métropoles: les nouveaux territoires du politique, Paris: Anthropos.

- (1996), «Où la culture politique territoriale fait l'institution: la cité métro politaine de Bologne», Revue Française de Sociologie.

Kantor, P.; Savitch, H., y VICarI, S. (1997), «The Political Economy of Urban Regimes: a comparative perspective», Urban Affairs Review, 32, 3: 348-377.

KleInman, M. (1999), «The business sector and the Greater London Authority», comunicación para la Conferencia de I'EURA Villes Européennes en transformation, París, 21-22 de octubre de 1999.

KREUKELS, A. (1999), «Cities, regions, provinces: new approaches of administrative restructuring in the Netherlands», Utrecht University, mimeo, $68 \mathrm{p}$.

LEFĖVE, C. (1997), De l'intercommunalité fonctionnelle à la supra-communalité politique, Boulogne-Billancourt: Informe para el Instituto de la Descentralización.

- (1998), «Metropolitan government and governance in OECD countries: a critical review», International Joumal of Urban and Regional Studies.

MiNomt, L. (1997), «Comment planifier l'aire métropolitaine Milanaise», Pouvoirs Locaux, 33, 2

RACo, M. (1998), «Assessing "institutional thickness" in the local context: a comparison of Cardiff and Sheffield», Environment and Planning A, 30: 975-996.

SCHMITTER, P., y LANZALACO, L. (1989), «Regions and the organization of Business interests», en COLEMAN, W., y JACEK, H., Regionalism, business interests and Public Policy, Sage studies in neo-corporatism, Sage, Londres.

SENAT (2000), «Pour une république territoriale: l'unité dans la diversité», estudio informativo núm. 447, París: Senado. 
TERHORST, P., y VAN DE VEN, J. (1999), «Uiban Trajectories, property rights and state structures: Amsterdam and Brussels compared», Communication à la Conférence de I'EURA «Villes Européennes en transformation», París, 21.22 de octubre de 1999 .

TRAVERS, T. (1997), «The governance of Paris and London», in CEBR et OEIL (1997), «Two great cities: a comparison of the Economies of London and Paris», Londres: Informe para la City Corporation of London.
Veutz, P. (1996), Villes, mondialisation et territoires, Paris: PUF.

WOOD, A. (1998), "Questions of scale in the entrepreneurial city», en T. HALl, y P. HubBard (ed.) (1998), The entrepreneurial city: Geographies of politio, regime and representation, Chichester: Wiley and Sons.

Wright, V., y CASSESE, S. (1997), La recomposition de l'État en Europe, Paris: La Découverte. 
